\title{
Predictors of incident malnutrition - a nutritionDay analysis in 11,923 nursing home residents
}

\author{
Gabriel Torbahn (DD ${ }^{1 凶}$, Isabella Sulz ${ }^{2}$, Franz Großhauser $^{1}$, Michael J. Hiesmayr $^{3}$, Eva Kiesswetter ${ }^{1}$, Karin Schindler ${ }^{4}$, Cornel C. Sieber $^{5}$, \\ Marjolein Visser ${ }^{6}$, Jasmin Weber ${ }^{1}$ and Dorothee Volkert ${ }^{1}$ \\ (c) The Author(s) 2021
}

BACKGROUND/OBJECTIVES: Malnutrition (MN) in nursing home (NH) residents is associated with poor outcome. In order to identify those with a high risk of incident $\mathrm{MN}$, the knowledge of predictors is crucial. Therefore, we investigated predictors of incident $\mathrm{MN}$ in older $\mathrm{NH}$-residents.

SUBJECTS/METHODS: NH-residents participating in the nutritionDay-project (nD) between 2007 and 2018, aged $\geq 65$ years, with complete data on nutritional status at $\mathrm{nD}$ and after 6 months and without MN at $\mathrm{nD}$. The association of 17 variables (general characteristics $(n=3)$, function $(n=4)$, nutrition $(n=1)$, diseases $(n=5)$ and medication $(n=4))$ with incident MN (weight loss $\geq$ $10 \%$ between $\mathrm{nD}$ and follow-up (FU) or BMI $\left(\mathrm{kg} / \mathrm{m}^{2}\right)<20$ at FU) was analyzed in univariate generalized estimated equation (GEE) models. Significant $(p<0.1)$ variables were selected for multivariate GEE-analyses. Effect estimates are presented as odds ratios and their respective $99.5 \%$-confidence intervals.

RESULTS: Of 11,923 non-malnourished residents, 10.5\% developed MN at FU. No intake at lunch (OR 2.79 [1.56-4.98]), a quarter (2.15 [1.56-2.97]) or half of the meal eaten (1.72 [1.40-2.11]) (vs. three-quarter to complete intake), the lowest BMI-quartile $(20.0-23.0)(1.86[1.44-2.40])$ (vs. highest $(\geq 29.1))$, being between the ages of 85 and 94 years $(1.46$ [1.05; 2.03]) (vs. the youngest age-group 65-74 years)), severe cognitive impairment (1.38 [1.04; 1.84]) (vs. none) and being immobile (1.28 [1.00-1.62]) (vs. mobile) predicted incident $\mathrm{MN}$ in the final model.

CONCLUSION: $10.5 \%$ of non-malnourished NH-residents develop MN within 6 months. Attention should be paid to high-risk groups, namely residents with poor meal intake, low BMI, severe cognitive impairment, immobility, and older age.

European Journal of Clinical Nutrition (2022) 76:382-388; https://doi.org/10.1038/s41430-021-00964-9

\section{INTRODUCTION}

The number of nursing home $(\mathrm{NH})$ residents was estimated by the number of beds at about 1.6 million in the US in 2015 and 4.0 million in Europe in 2017 [1]. NH-residents are at high risk of malnutrition which is reported in up to $54 \%$, depending on the definition and cutoff value used [2-5]. Malnutrition is associated with poor health and functional outcomes as well as higher health care costs [6-11]. Therefore, malnutrition is a burden for the persons affected and for the health care system, and its prevention of utmost importance.

\section{Currently, little is known about the development of malnutrition in NH-residents over time \\ Many factors are associated with malnutrition in cross-sectional studies. In a systematic review, including studies with at least $100 \mathrm{NH}-$ residents each, depression, poor oral intake, swallowing disorders, chewing problems, and eating dependency were associated with weight loss (WL) in 6 studies, and immobility and dependence in}

activities of daily living (ADL), poor oral intake, chewing problems, dysphagia and female sex were associated with low Body Mass Index (BMI) in 7 studies [12]. Since these cross-sectional results do not allow conclusions about the direction of the associations, longitudinal studies are needed. Up to now, only four longitudinal studies examined this association in $\mathrm{NH}$-residents, which found cognitive decline [13], lower functional status/ higher dependency in ADL [14, 15], constipation [16], hospitalization [14], eating dependency [16], and low appetite $[15,16]$ as risk factors of malnutrition. These results are however based on rather small samples of 108 [15] to 441 [16] residents, and other eventually important risk factors, such as low food intake, might be missing. Most important, residents who were already malnourished at baseline were not excluded, resulting in different probabilities to develop malnutrition within each sample.

Based on repeated measurements data, a decline in nutritional status (based on low BMI, unintentional WL, low nutritional intake) was observed in $23 \%$ of $\mathrm{NH}$-residents within 1 year [17]. A 2-year

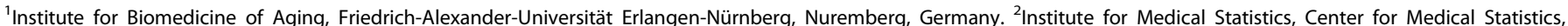

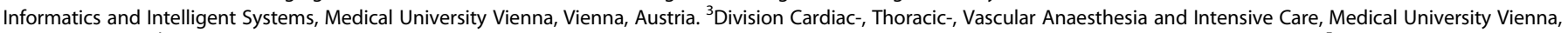

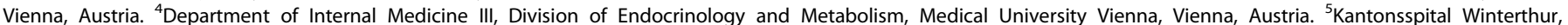

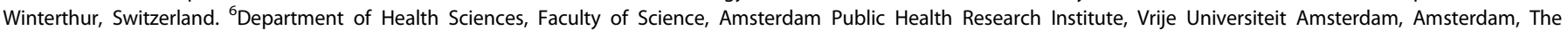
Netherlands. ${ }^{\circledR}$ email: gabriel.torbahn@fau.de 
incidence of $26 \%$ according to the MNA-SF ( $<8$ points) has been described [14], and for a period of 6 months, 26 and $2 \%$ incident malnourished cases according to weight loss (WL) of $\geq 2 \mathrm{~kg}$ [15] and $>10 \%[16]$ have been reported.

Identification of factors increasing the risk and predicting the development of malnutrition is of utmost importance to help prevent malnutrition and its negative consequences. Thus, our aims were to examine the incidence of malnutrition and to identify predictors of incident malnutrition in a large sample of $\mathrm{NH}$-residents.

\section{MATERIALS/SUBJECTS AND METHODS Reporting}

This manuscript adheres to the reporting standards for observational studies (STROBE-statement (Supplemental material, Table 1)) $[18,19]$.

\section{Study design}

This analysis is part of the Joint Action Malnutrition in the Elderly Knowledge Hub (MaNuEL) of the European Joint Programming Initiative A Healthy Diet for a Healthy Life (JPI-HDHL) that investigated determinants and risk factors for (incident) malnutrition in older people in different settings [20-24] and is based on the nutritionDay-project (nD) (NCT04202939). The nD-project is a worldwide survey, performed annually in hospitals and $\mathrm{NHs}$ [25-27] with a follow-up (FU) after six months in the $\mathrm{NH}$-setting [27]. The project is supported by the European Society for Clinical Nutrition and Metabolism (ESPEN) and national medical societies and is promoted via the internet, emails, newsletters, reports and at national and international congresses (e.g. of ESPEN and European Geriatric Medicine Society (EuGMS)). Resident and ward characteristics are assessed by standardized questionnaires which are available in more than 30 languages (https://www.nutritionday.org/). The nDproject was approved by the ethical committee of the Medical University of Vienna, Austria, by the ethical committee of the Friedrich-Alexander-Universität Erlangen-Nürnberg, Germany and by local ethical committees as required by national rules. All residents or their legal representatives gave written or oral consent prior to participation and all information was assessed completely anonymised.

\section{Inclusion and exclusion criteria}

We included $\mathrm{NH}$-residents aged 65 years or older participating in the nD-project between 2007 and 2018. Residents without data on body weight at FU were excluded as well as residents from Japan due to major differences in the nursing home system [28] and a consistently lower BMI in Japanese residents [29]. Further, residents with missing data on BMI or WL at baseline and those with malnutrition at baseline (defined by $\mathrm{BMl}<20 \mathrm{~kg} / \mathrm{m}^{2}$ and/or $\mathrm{WL}$ of $>5 \mathrm{~kg}$ in the past year (assessed via questionnaire)) were excluded to gain data on real incidence.

\section{Acquisition of data}

Questionnaires were completed by local NH staff. Body weight in kilogram $(\mathrm{kg})$ was measured using scales from the $\mathrm{NH}$ wards at $\mathrm{nD}$ and $\mathrm{FU}$, or the most recent weight documented in the nursing records was used for both dates. $\mathrm{NH}$ staff was asked to measure body height using a stadiometer for residents who were able to stand. If this was not possible, height was extrapolated based on the measurement of knee height or was recorded from the information in nursing records or identification cards. BMI was calculated according to body weight $(\mathrm{kg}) /$ height $(\mathrm{m})^{2}$. Height at $\mathrm{nD}$ was used for calculation of $\mathrm{BMI}$ at $\mathrm{nD}$ and $\mathrm{FU}$.

\section{Outcome}

Incident [30] malnutrition was defined as $\mathrm{BMI}<20 \mathrm{~kg} / \mathrm{m}^{2}$ and/or $\mathrm{WL} \geq 10 \%$ between $\mathrm{nD}$ and $\mathrm{FU}$, which was calculated as body weight difference between the two points in time.
Table 1. Baseline Characteristics.

Variable

NH-residents with MN-data at FU $(n=$ 11,923)

Age (years)

65-74

$1442(12.1 \%)$

$75-84$

$3428(28.8 \%)$

$5804(48.7 \%)$

$1249(10.5 \%)$

95-107

$3801(31.9 \%)$

Male

Female

$8122(68.1 \%)$

BMI $\left(\mathrm{kg} / \mathrm{m}^{2}\right)$

20.0-22.9

$2981(25.0 \%)$

23.0-25.6

2981 (25.0\%)

25.7-29.0

$2993(25.1 \%)$

$2968(24.9 \%)$

Mobility

Mobile

4702 (39.4\%)

Partially mobile

4274 (35.8\%)

Immobile

$2902(24.3 \%)$

$45(0.4 \%)$

Cognitive impairment

None

$4334(36.3 \%)$

Slight to moderate

$4793(40.2 \%)$

Severe

$2761(23.2 \%)$

$35(0.3 \%)$

Dysphagia

No

10697 (89.7\%)

$1082(9.1 \%)$

$144(1.2 \%)$

Missing

$9742(81.7 \%)$

Chewing problems

No

$2032(17.0 \%)$

Yes

$149(1.2 \%)$

Intake at lunch

Three-quarters to all

$8181(68.6 \%)$

Half

$2623(22.0 \%)$

$624(5.2 \%)$

$143(1.2 \%)$

Nothing

$120(1.0 \%)$

Nothing because of artificial nutrition

$232(1.9 \%)$

$11380(95.4 \%)$

No

$543(4.6 \%)$

$3613(30.3 \%)$

$8310(69.7 \%)$

Yes

$7808(65.5 \%)$

Musculoskeletal diseases

No

4115 (34.5\%)

Cardiovascular/pneumological diseases

No

$5911(49.6 \%)$

Yes

$6012(50.4 \%)$

Other diseases

No

$9421(79.0 \%)$

Yes

$2502(21.0 \%)$

Antibiotics

No

$11433(95.9 \%)$

Yes

$345(2.9 \%)$ 


\begin{tabular}{|c|c|}
\hline Variable & $\begin{array}{l}\text { NH-residents } \\
\text { with MN-data } \\
\text { at FU }(n= \\
11,923)\end{array}$ \\
\hline \multicolumn{2}{|l|}{ Opiates } \\
\hline No & $10002(83.9 \%)$ \\
\hline Yes & $1766(14.8 \%)$ \\
\hline Missing & $155(1.3 \%)$ \\
\hline \multicolumn{2}{|c|}{ Psychoactive substances } \\
\hline No & $6322(53.0 \%)$ \\
\hline Yes & $5460(45.8 \%)$ \\
\hline Missing & $141(1.2 \%)$ \\
\hline \multicolumn{2}{|c|}{ Number of drugs } \\
\hline$<5$ drugs & $2714(22.8 \%)$ \\
\hline$>=5$ drugs & $9043(75.8 \%)$ \\
\hline Missing & $166(1.4 \%)$ \\
\hline
\end{tabular}

\section{Potential predictors}

Seventeen variables in 5 categories were included as potential predictors of incident malnutrition:

General characteristics (3 variables): age (65-74, 75-84, 85-94, 95-107 years), sex (female/male), BMI (quartiles: 20.0-22.9, 23.0-25.6, 25.7-29.0, 29.1-64.7 kg/m²).

Function (4 variables): mobility (mobile: able to leave the $\mathrm{NH}$; partially mobile: able to get out of bed or chair without help of another person but unable to leave the $\mathrm{NH}$ unit; immobile: bound to a bed or (wheel)chair and unable to stand up without any help by other persons), cognitive impairment (none, slight to moderate, severe; classified by NH staff based on established classification criteria such as Mini Mental Status Test or, if not available, according to their subjective estimation), dysphagia (yes/no), chewing problems (yes/no).

Nutrition (1 variable): intake at lunch (three-quarters to all, half, a quarter, nothing, nothing because of artificial nutrition).

Diseases (5 variables): diagnosis of cancer (yes/no), neurologic diseases (e.g. dementia, stroke) (yes/no), musculoskeletal diseases (e.g. rheumatoid arthritis, osteoporosis) (yes/no), cardiovascular/ pneumological diseases (yes/no), other diseases (yes/no).

Medication (4 variables): intake of antibiotics (yes/no), opiates (yes/no), psychoactive substances (yes/no) and number of drugs $(<5 / \geq 5)$.

\section{Statistical analysis}

Potential predictors are described by median with minimum and maximum for continuous variables (age and BMI) and by absolute numbers, percentages for categorical variables.

For categorical variables with more than $0.1 \%$ missing values, we added a missing category. Cases with missing values in a variable with less than $0.1 \%$ missing values (tube feeding, parenteral nutrition, and cancer) and cases with missing values for age or sex were excluded.

To assess associations between potential predictors and incident malnutrition, we conducted multivariate generalized estimating equation (GEE) analyses with $\mathrm{NH}$-ward as cluster variable. Each potential predictor was first analyzed for its association with incident malnutrition in univariate GEE analyses. All variables with a $p$-value $p<0.1$ were tested for multicollinearity (variation influence factor (VIF)) and those with a VIF $<5$ were added to the multivariate model. A $p$-value of $p<0.005$ was defined as significant in the final model [31, 32]. We tested potential interactions according to sex. Results are presented as odds ratios (OR) with the corresponding 99.5\%-confidence intervals $(99.5 \%-\mathrm{Cl})$. Complete case analyses were conducted as sensitivity analyses. To describe the accuracy of the final model, we present the area under the curve (AUC).

All statistical analyses were performed using $\mathrm{R}$ version 3.6.1.

\section{RESULTS}

Overall, 39,840 residents were assessed at nD between 2007 and 2018. For 20,443 residents, information on body weight at FU was missing, and 2,160 were $<65$ years of age. Ninety-eight residents from Japan were excluded as well as 1,280 residents with missing data on $\mathrm{WL}$ before $\mathrm{nD}$ or $\mathrm{BMI}$ at $\mathrm{nD}$. 3,859 residents were malnourished at baseline $(1,253$ with $\mathrm{WL}>5 \mathrm{~kg}$ before $\mathrm{nD}$ and 2,606 with $\mathrm{BMI}<20 \mathrm{~kg} / \mathrm{m}^{2}$ at $\mathrm{nD}$ ) and thus also excluded. Seventyseven with missing values in age or sex at baseline or because of a missing value in variables with $<0.1 \%$ missing values were excluded, resulting in 11,923 residents from North America and Europe included in the analyses (see flow chart, Fig. 1).

\section{Baseline characteristics}

Median age was 86.0 [65.0-107.0] years and $68.1 \%$ were female. Median BMI was 25.7 [20.0-64.8] kg/m², $24.3 \%$ were immobile and $23.2 \%$ had severe cognitive impairment. Further characteristics are described in Table 1.

\section{Incident malnutrition}

At 6-month FU, 953 residents (8.0\%) had a WL $\geq 10 \%$ and 586 (4.9\%) had a BMl $<20 \mathrm{~kg} / \mathrm{m}^{2}$, while in 290 residents $(2.4 \%)$ both criteria were present simultaneously. Therefore, 1,249 (10.5\%) residents developed malnutrition according to one or both of the two criteria.

\section{Predictors of incident malnutrition}

All potential predictors except tube feeding, parenteral nutrition, cancer, cardiovascular/pneumological diseases, other diseases and antibiotics were associated with incident malnutrition in the univariate model with $p<0.1$ (Supplemental material, Table 2). There was no indication for multicollinearity. Interaction according to sex acquired significance only for BMI-group 20.0-22.9. For male NH residents in this subgroup, the odds for incident malnutrition was higher than for females. The multivariate model included 13 variables univariately associated with incident malnutrition (AUC 0.68). No intake at lunch (OR 2.79 [1.56-4.98]), a quarter (OR 2.15 [1.56-2.97]) or half of the meal eaten at lunch (OR 1.72 [1.40-2.11]) (vs. three-quarter to complete intake), the lowest BMI-quartile $\left(20.0-22.9 \mathrm{~kg} / \mathrm{m}^{2}\right)(\mathrm{OR} 1.86$ [1.44-2.40]) (vs. highest BMI-quartile $\left.\left(29.1-64.8 \mathrm{~kg} / \mathrm{m}^{2}\right)\right)$, the age-group 85-94 years (OR 1.46 [1.05; 2.03]) (vs. 65-74 years)), severe cognitive impairment (OR $1.38[1.04 ; 1.84])$ (vs. none) and being immobile (OR 1.28 [1.00-1.62]) (vs. mobile) predicted incident malnutrition in the final model (Fig. 2). In the sensitivity analysis including only complete cases $(n=11,170)$, associations and effect sizes were similar, only immobility could not retain significance (Supplemental material, Fig.1).

\section{DISCUSSION}

In a large, international sample of 11,923 non-malnourished $\mathrm{NH}$ residents, $10.5 \%$ developed malnutrition within 6 months. Among 17 potential predictors, no or limited food intake at lunch, low BMl, severe cognitive impairment, immobility, and age 85-94 years were identified as predictors of incident malnutrition.

We defined malnutrition as low BMI and/or a significant $\mathrm{WL}$, based on international agreement for several analyses within the MaNuEL Knowledge Hub. These variables represent two phenotypic criteria of the Global Leadership Initiative on Malnutrition (GLIM) global consensus definition [33], are widely used and were selected because of their availability in several data sets used for secondary data analyses. Complete information to apply the GLIM 


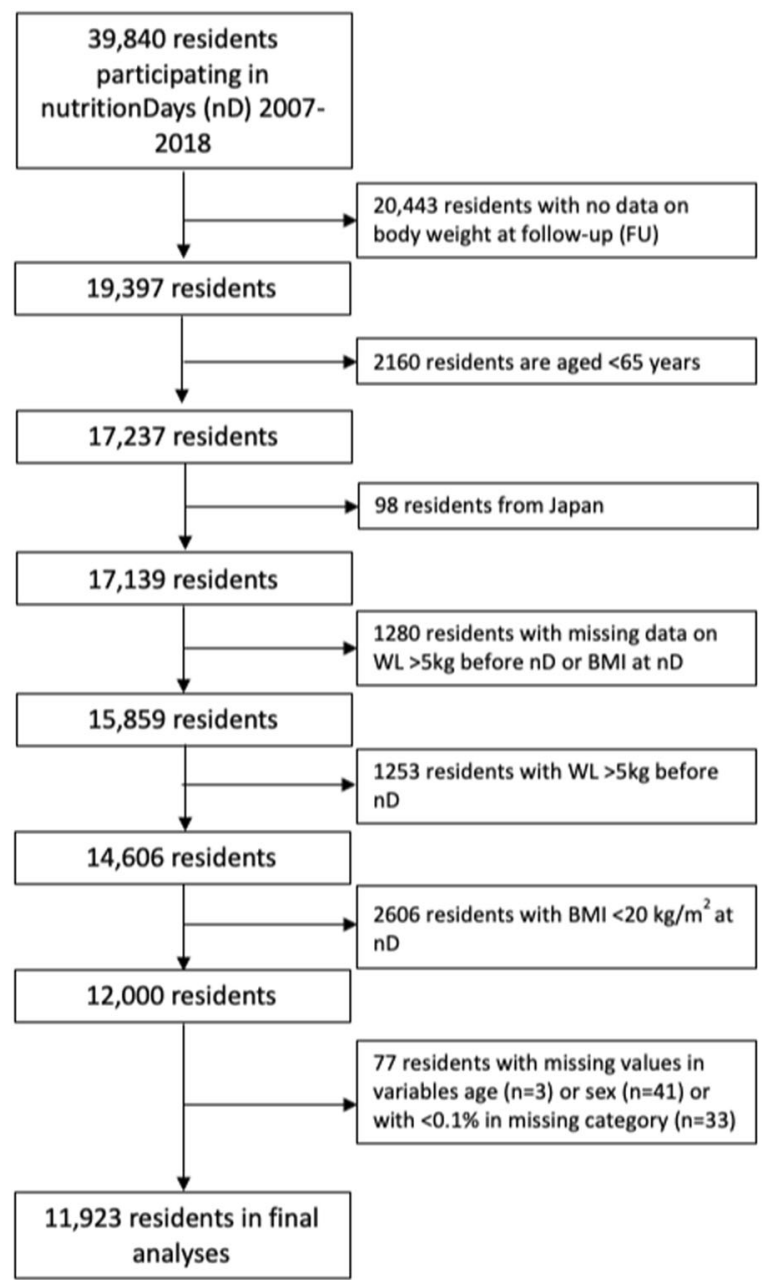

Fig. 1 Study flow-chart. Flow of study participants.

definition, e.g. muscle mass, is currently unfortunately not available in the $\mathrm{nD}$ data set.

The incidence of malnutrition at 6 months according to our definition was $10.5 \%$, with $8.0 \%$ according to the WL-criterion and 4.9\% according to the low BMl-criterion. Data on incident malnutrition in $\mathrm{NH}$-residents is scarce and hardly comparable due to different definitions of malnutrition, different methods to assess malnutrition (e.g. measurement vs. self-report), and different FU-periods. Beck reported a WL of $\geq 10 \%$ within 6 months in only $2.1 \%$ of $\mathrm{NH}$-residents [16] and Mamhidir et al. [34] reported a WL of $\geq 10 \%$ in $14 \%$ of older adults, however, within 1 year and in sheltered housing. In contrast to these studies, we excluded residents with malnutrition at baseline to consider only those with a potential risk to develop malnutrition and thus report true incidence. Although Beck [16] reported a markedly lower percentage of residents with a measured $\mathrm{WL}$ of $\geq 10 \%$ within 6 months, our data might be underestimated due to a high number of residents without FU-data, since residents with missing body weight and those who died, which were excluded from our sample, might have developed malnutrition more often. Nursing homes or wards that did not take part at the FU assessment might have been less interested in nutritional issues which could affect a poorer nutritional management when compared to nursing homes or wards with FU.

Residents aged 85-94 years were more likely to develop malnutrition compared to residents aged 65-74 years. While chances for the other age groups were also higher compared to the reference group, they did not show significance which could be due to the statistical power: nearly half of all participants were in the age group 85-94 years (see Table 1). Other prospective studies in $\mathrm{NH}$ did not find a significant association between age and (incident) WL [15] or deteriorating nutritional status according to MNA-SF [14]. In contrast to these analyses, age-and also BMIwere entered as categorical variables in our models, as results might be easier for interpretation and applicability in the clinical setting, and effects might be different for lower and higher values.

In our analyses, the lowest BMI-group (20.0-22.9) had a 1.86 times higher chance of incident malnutrition (Fig. 2) which seems reasonable, as residents with a BMI close to the cut-off of $20 \mathrm{~kg} / \mathrm{m}^{2}$ at baseline may be more likely to develop malnutrition according to our definition than those with a higher BMI. Previous studies also reported this association, although they did not exclude residents with malnutrition at baseline [15, 35].

Dietary intake was assessed by observation during the lunch on $\mathrm{nD}$. Overall, $22.0 \%$ consumed only half of the served portion, $5.2 \%$ a quarter, and $1.2 \%$ ate nothing at all. The chance of developing malnutrition increased, the lower the intake at lunch (Fig. 2). Unfortunately, intake at lunch is the only meal assessed at $\mathrm{nD}$. Intake at lunch may depend on habits formed earlier [36], the timing of meal in the $\mathrm{NH}$ [37], and may differ from country to country due to different cultural habits [38]. However, Hiesmayr et al. showed that food intake assessed via plate diagrams was similar for breakfast, lunch, and dinner for patients in hospitals [25]. Additionally, in NH lunch is an important main meal and is often the only warm dish during the day [39] in many countries which suggests that this meal is an important indicator of daily food intake. Our results support those from cross-sectional studies showing that poor oral intake is associated with malnutrition, low BMI and WL $[12,40]$, emphasizing the importance of adequate food intake.

An adequate nutritional intake might not only lower the risk of malnutrition but also of mortality. In an earlier analysis from the nD-project, Streicher et al. showed that a low intake at lunch was associated with a higher risk of mortality in malnourished residents [41]. It has also been shown that mortality of $\mathrm{NH}$ residents is predicted by WL and low BMI [42]. Therefore, future analyses should investigate whether $\mathrm{WL}$ and low BMI are mediators of the association between low food intake and mortality. Low food intake may be caused by a variety of factors such as functional limitations, psychological factors, or end-of-life situation. Thus, for a better understanding, also reasons for low or no intake need to be evaluated further.

Residents with severe cognitive impairment showed a 1.4-fold chance for incident malnutrition compared to those with a good cognitive status. The chance was also increased for those being slightly to moderately impaired but the result was not significant. Lannering et al. also showed that cognitive impairment at baseline is associated with malnutrition at FU [13]. It is well known and confirmed by recent studies, that a poor cognitive status is associated with low meal/energy intake $[43,44]$. The occurrence of nutrition/mealtime-related problems such as olfactory and taste dysfunction, attention deficit, behavioral problems, or refusal to eat have repeatedly been described with declining cognitive abilities [45]. A longitudinal study reported a significant relationship between cognitive dysfunction and a higher risk for WL [13] but causal pathways should be further investigated.

Further, immobile residents had a higher chance (OR 1.28 [1.02-1.59]) to develop malnutrition compared to mobile residents. This is in line with results from a systematic review of cross-sectional studies which reported an association between low BMl and immobility in several studies [12]. Two longitudinal studies that investigated the association between baseline characteristics and malnutrition at FU also reported a significant association between poor functional status and malnutrition $[14,15]$. In residents with dementia, problems with bringing food to the mouth are associated with loss of weight [46], while an uncomfortable position during the 


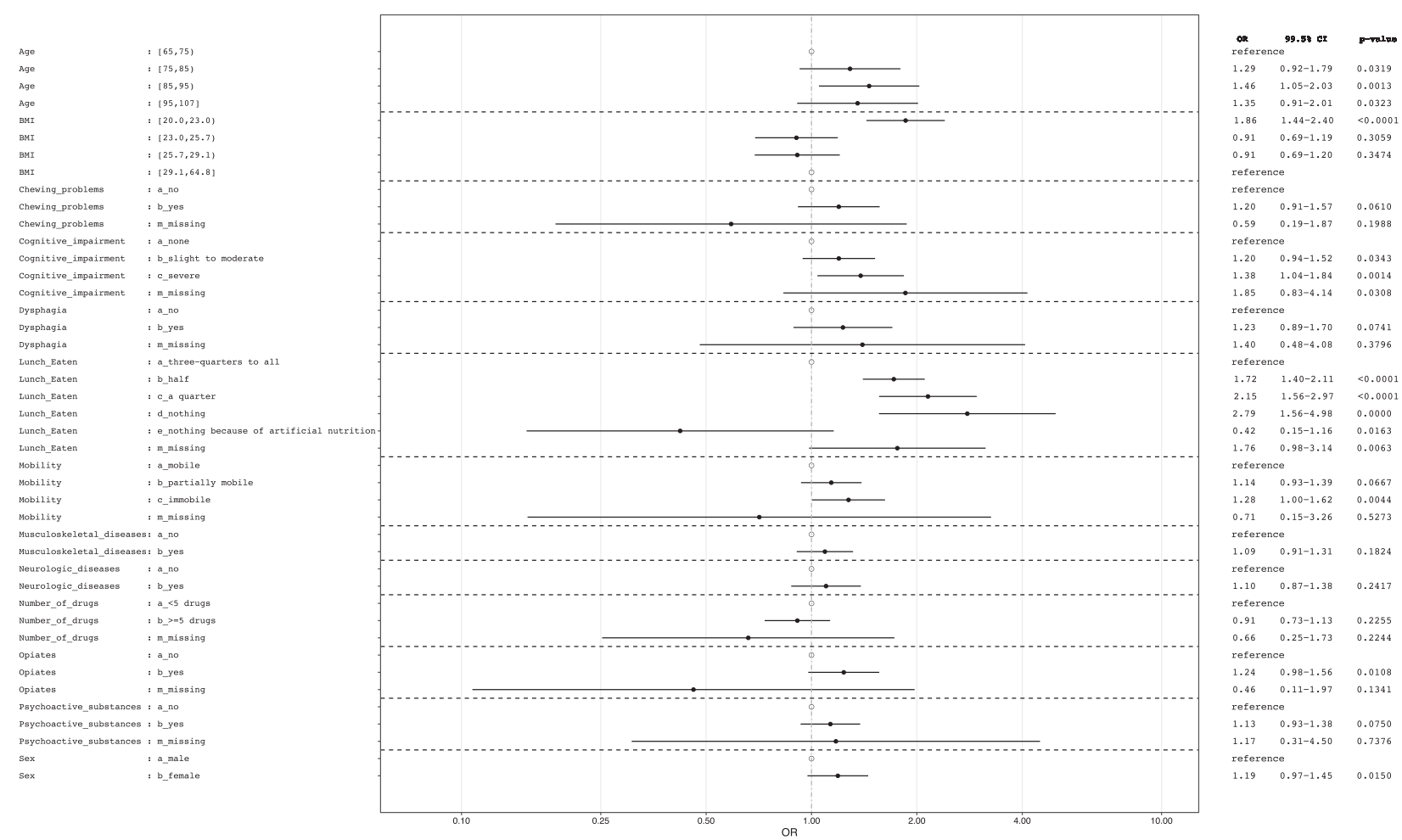

Fig. 2 Chance for incidence of malnutrition according to different patient characteristics. Results of multivariate GEE-analyses $(n=11,923)$; OR: Odds ratio; $99.5 \%$-Cl: $99.5 \%$-Confidence interval; cases with a percentage of $<0.1$ in missing category and those with missing values in age and sex were excluded from analyses $(n=77)$.

meal might deteriorate food intake in immobile residents [47]. In the sensitivity analysis, the association between immobility and incident malnutrition was similar but a little bit smaller (OR 1.25 [1.00-1.57]), and significance was not retained. One explanation might be the loss of power due to the exclusion of $n=753$ residents with missing values in any of the included variables. For all other variables, results have not been changed, showing the robustness of our results in general.

Depending on the malnutrition screening tool used in the $\mathrm{NH}$ setting [48], our identified predictors for incident malnutrition are already assessed during malnutrition screening but some tools do not consider any of these risk factors. Therefore, future studies should further investigate whether a low intake at lunch, a low BMI, immobility, severe cognitive impairment, and older age might further improve malnutrition screening tools in $\mathrm{NH}$-residents.

\section{Strengths and limitations}

Our study has several strengths. First, we could include a very large sample from different countries and different care systems. The questionnaires were standardized and available in different languages. Second, we present data on incident malnutrition which are very rare so far by excluding residents with malnutrition at baseline to reduce the risk of wrong causation. Third, we were able to consider a large set of variables from different domains to investigate the potential prediction of incident malnutrition. Moreover, we report our analyses according to a standardized reporting guideline (STROBE-statement) to ensure transparent and thorough reporting.

However, when interpreting our results, several limitations must be considered. First, data were assessed by local staff and not by trained scientific personnel. Data presented here are mostly assessed as part of daily routine with simple and quick methods and not via validated scales (such as Katz or Barthel Index for ADL). Our analyses are limited to the variables available in the $\mathrm{nD}$ dataset, and eventually relevant potential predictors, e.g. ADL, multimorbidity, or hospitalisation, could not be taken into account. Food intake on $\mathrm{nD}$ was assessed estimating the consumed amount of food via a plate diagram and not via dietary records or other more valid-but also more timeconsuming - dietary assessment methods [49]. Thirdly, follow-up data at 6 months was not available for many residents, and we cannot exclude a respective selection bias. In addition, external validity may be limited due to selection bias by exclusion of residents with missing data on WL or BMI at baseline. Also, by inclusion of only those $\mathrm{NH}$ with FU, which might have been more interested in nutritional issues, the incidence of malnutrition might have been underestimated and may limit external validity. Finally, all observational studies are open to residual and unmeasured confounding [50].

\section{CONCLUSIONS AND IMPLICATIONS}

In this large $\mathrm{nD}$ data set, 6-month incidence of malnutrition in nursing-home residents was $10.5 \%$. A low intake at lunch, a low BMI, immobility, severe cognitive impairment and older age were identified as predictors for the development of malnutrition.

\section{Implications for practice}

While older age represents a non-modifiable factor, it is also of importance since special attention should be given to older residents to timely start with respective preventive interventions. In contrast, functional and cognitive impairments represent at least partly modifiable risk factors. Beneficial effects of physical exercise and cognitive training interventions are on physical and cognitive status are well known, which might also affect the nutritional status positively. In case of severe functional or cognitive impairment, at least special attention should be given to these residents. Food intake also represents a modifiable risk factor, and if food intake (at lunch) is low, effective nutritional care strategies with a potential to prevent malnutrition (e.g. feeding assistance, pleasant environment, or sharing of mealtimes with others) are available and should be offered. 


\section{Implications for research}

Further prospective, large-scale cohort studies in nursing homes with longer follow-up periods and repeated measurements of nutritional status including reasons for WL (e.g. voluntary vs involuntary) and reasons for low intake should be conducted to complement and extent our results. In addition, food intake should be assessed more detailed, and reasons for drop-out should be recorded. Finally, it should be investigated whether inclusion of our identified risk factors in malnutrition screening tools will improve nutritional care and health outcomes.

\section{REFERENCES}

1. OECD. Long-Term Care Rescources and Utilisation: Beds in residential long-term care facilities. Available at https://stats.oecd.org/lndex. aspx?DataSetCode=HEALTH_LTCR\#. Accessed January 07, 2021.

2. Cereda E, Pedrolli C, Klersy C, Bonardi C, Quarleri L, Cappello S, et al. Nutritional status in older persons according to healthcare setting: a systematic review and meta-analysis of prevalence data using MNA((R)). Clin Nutr. 2016;35:1282-90. https://doi.org/10.1016/j.clnu.2016.03.008. e-pub ahead of print 2016/04/18

3. Kiesswetter E, Colombo MG, Meisinger C, Peters A, Thorand B, Holle R et al. Malnutrition and related risk factors in older adults from different health-care settings: an enable study. Public Health Nutr 2019: 1-11. e-pub ahead of print 2019/08/28; https://doi.org/10.1017/s1368980019002271

4. Namasivayam AM, Steele CM. Malnutrition and Dysphagia in long-term care: a systematic review. J Nutr Gerontol Geriatr. 2015;34:1-21. https://doi.org/10.1080/ 21551197.2014.1002656. e-pub ahead of print 2015/03/25

5. Wolters M, Volkert D, Streicher M, Kiesswetter E, Torbahn G, O'Connor EM, et al. Prevalence of malnutrition using harmonized definitions in older adults from different settings - A MaNuEL study. Clin Nutr. 2019;38:2389-98. https://doi.org/ 10.1016/j.clnu.2018.10.020. e-pub ahead of print 2018/11/19

6. Abizanda P, Sinclair A, Barcons N, Lizan L, Rodriguez-Manas L. Costs of malnutrition in institutionalized and community-dwelling older adults: a systematic review. J Am Med Dir Assoc. 2016;17:17-23. https://doi.org/10.1016/j. jamda.2015.07.005. e-pub ahead of print 2015/12/30

7. Chen LY, Liu LK, Hwang AC, Lin MH, Peng LN, Chen LK, et al. Impact of malnutrition on physical, cognitive function and mortality among older men living in veteran homes by minimum data set: a prospective cohort study in Taiwan. J Nutr Health Aging. 2016;20:41-47. https://doi.org/10.1007/s12603-015-0646-1. epub ahead of print 2016/01/06

8. Lilamand M, Kelaiditi E, Demougeot L, Rolland Y, Vellas B, Cesari M. The Mini Nutritional Assessment-Short Form and mortality in nursing home residentsresults from the INCUR study. J Nutr Health Aging. 2015;19:383-8. https://doi.org/ 10.1007/s12603-014-0533-1. e-pub ahead of print 2015/03/27

9. Meijers JM, Halfens RJ, Wilson L, Schols JM. Estimating the costs associated with malnutrition in Dutch nursing homes. Clin Nutr. 2012;31:65-68. https://doi.org/ 10.1016/j.clnu.2011.08.009. e-pub ahead of print 2011/09/02

10. Torma J, Winblad U, Cederholm T, Saletti A. Does undernutrition still prevail among nursing home residents? Clin Nutr. 2013;32:562-8. https://doi.org/ 10.1016/j.clnu.2012.10.007. e-pub ahead of print 2012/11/10

11. Veronese N, Cereda E, Solmi M, Fowler SA, Manzato E, Maggi S, et al. Inverse relationship between body mass index and mortality in older nursing home residents: a meta-analysis of 19,538 elderly subjects. Obes Rev. 2015;16:1001-15. https://doi.org/10.1111/obr.12309. e-pub ahead of print 2015/08/08

12. Tamura BK, Bell CL, Masaki KH, Amella EJ. Factors associated with weight loss, low BMI, and malnutrition among nursing home patients: a systematic review of the literature. J Am Med Dir Assoc. 2013;14:649-55. https://doi.org/10.1016/j. jamda.2013.02.022. e-pub ahead of print 2013/05/04

13. Lannering C, Ernsth Bravell M, Midlöv P, Östgren CJ, Mölstad S. Factors related to falls, weight-loss and pressure ulcers-more insight in risk assessment among nursing home residents. J Clin Nurs. 2016;25:940-50. https://doi.org/10.1111/ jocn.13154. e-pub ahead of print 2016/01/28

14. Izawa S, Enoki H, Hasegawa J, Hirose T, Kuzuya M. Factors associated with deterioration of mini nutritional assessment-short form status of nursing home residents during a 2-year period. J Nutr Health Aging. 2014;18:372-7. https://doi. org/10.1007/s12603-013-0400-5. e-pub ahead of print 2014/03/29

15. Knoops KT, Slump E, de Groot LC, Wouters-Wesseling W, Brouwer ML, van Staveren WA. Body weight changes in elderly psychogeriatric nursing home residents. J Gerontol A Biol Sci Med Sci. 2005;60:536-9. https://doi.org/10.1093/ gerona/60.4.536. e-pub ahead of print 2005/06/04

16. Beck AM. Weight loss, mortality and associated potentially modifiable nutritional risk factors among nursing home residents-a Danish follow-up study. J Nutr Health Aging. 2015;19:96-101. https://doi.org/10.1007/s12603-015-0439-6. e-pub ahead of print 2015/01/07
17. Bauer S, Halfens RJG, Lohrmann C. Changes in nutritional status in nursing home residents and associated factors in nutritional status decline: a secondary data analysis. J Adv Nurs. 2017;73:2420-9. https://doi.org/10.1111/jan.13297

18. Vandenbroucke JP, von Elm E, Altman DG, Gotzsche PC, Mulrow CD, Pocock SJ, et al. Strengthening the reporting of observational studies in epidemiology (STROBE): explanation and elaboration. PLoS Med. 2007;4:e297 https://doi.org/ 10.1371/journal.pmed.0040297. e-pub ahead of print 2007/10/19

19. von Elm E, Altman DG, Egger M, Pocock SJ, Gotzsche PC, Vandenbroucke JP. The strengthening the reporting of observational studies in epidemiology (STROBE) Statement: guidelines for reporting observational studies. Int J Surg. 2014;12:1495-9. https://doi.org/10.1016/j.jisu.2014.07.013. e-pub ahead of print 2014/07/22

20. O'Keeffe M, Kelly M, O'Herlihy E, O'Toole PW, Kearney PM, Timmons S, et al. Potentially modifiable determinants of malnutrition in older adults: A systematic review. Clin Nutr. 2018. https://doi.org/10.1016/j.clnu.2018.12.007. e-pub ahead of print 2019/01/28

21. Streicher M, van Zwienen-Pot J, Bardon L, Nagel G, Teh R, Meisinger $C$, et al. Determinants of incident malnutrition in community-dwelling older adults: a MaNuEL multicohort meta-analysis. J Am Geriatr Soc. 2018;66:2335-43. https:// doi.org/10.1111/jgs.15553. e-pub ahead of print 2018/08/24

22. Visser M, Volkert D, Corish C, Geisler C, de Groot LC, Cruz-Jentoft AJ, et al. Tackling the increasing problem of malnutrition in older persons: the Malnutrition in the Elderly (MaNuEL) Knowledge Hub. Nutr Bull. 2017;42:178-86. https://doi.org/ $10.1111 / \mathrm{nbu} .12268$

23. Volkert D, Kiesswetter E, Cederholm T, Donini LM, Eglseer D, Norman K, et al. Development of a model on determinants of malnutrition in aged persons: a MaNuEL project. Gerontol Geriatr Med. 2019;5:2333721419858438 https://doi. org/10.1177/2333721419858438. e-pub ahead of print 2019/07/02

24. Volkert D, Visser M, Corish CA, Geisler C, de Groot L, Cruz-Jentoft AJ, et al. Joint action malnutrition in the elderly (MaNuEL) knowledge hub: summary of project findings. Eur Geriatr Med. 2020;11:169-77. https://doi.org/10.1007/s41999-01900264-3. e-pub ahead of print 2020/04/17

25. Hiesmayr M, Schindler K, Pernicka E, Schuh C, Schoeniger-Hekele A, Bauer $P$, et al. Decreased food intake is a risk factor for mortality in hospitalised patients: the NutritionDay survey 2006. Clin Nutr. 2009;28:484-91. https://doi.org/10.1016/j. clnu.2009.05.013. e-pub ahead of print 2009/07/01

26. Schindler K, Pichard C, Sulz I, Volkert $D$, Streicher $M$, Singer $P$, et al. nutritionDay: 10 years of growth. Clin Nutr. 2017;36:1207-14. https://doi.org/10.1016/j. clnu.2016.11.004. e-pub ahead of print 2016/12/06

27. Valentini L, Schindler K, Schlaffer R, Bucher H, Mouhieddine M, Steininger $K$, et al. The first nutritionDay in nursing homes: participation may improve malnutrition awareness. Clin Nutr. 2009;28:109-16. https://doi.org/10.1016/j.clnu.2009.01.021. e-pub ahead of print 2009/03/07

28. Ribbe MW, Ljunggren G, Steel K, Topinkova E, Hawes C, Ikegami N, et al. Nursing homes in 10 nations: a comparison between countries and settings. Age Ageing 1997;26(Suppl 2):3-12. https://doi.org/10.1093/ageing/26.suppl_2.3. e-pub ahead of print 1998/02/17

29. WHO expert consultation. Appropriate body-mass index for Asian populations and its implications for policy and intervention strategies. Lancet. 2004;363:157-63. https://doi.org/10.1016/s0140-6736(03)15268-3. e-pub ahead of print 2004/01/17

30. Porta M Incidence. In: A dictionary of epidemiology: Oxford university press, 2014.

31. loannidis JPA. The proposal to lower $P$ value Thresholds to .005 . JAMA. 2018;319:1429-30. https://doi.org/10.1001/jama.2018.1536. e-pub ahead of print 2018/03/23

32. Benjamin DJ, Berger JO, Johannesson M, Nosek BA, Wagenmakers EJ, Berk R, et al. Redefine statistical significance. Nat Hum Behav. 2018;2:6-10. https://doi.org/ 10.1038/s41562-017-0189-z

33. Cederholm T, Jensen GL, Correia MITD, Gonzalez MC, Fukushima R, Higashiguchi T, et al. GLIM criteria for the diagnosis of malnutrition - A consensus report from the global clinical nutrition community. Clin Nutr. 2019;38:1-9. https://doi.org/ 10.1016/j.clnu.2018.08.002. e-pub ahead of print 2018/09/03

34. Mamhidir AG, Ljunggren G, Kihlgren M, Kihlgren A, Wimo A. Underweight, weight loss and related risk factors among older adults in sheltered housing-a Swedish follow-up study. J Nutr Health Aging. 2006;10:255-62. e-pub ahead of print 2006/08/04

35. Volicer L, Frijters DH, van der Steen JT. Apathy and weight loss in nursing home residents: longitudinal study. J Am Med Dir Assoc. 2013;14:417-20. https://doi. org/10.1016/j.jamda.2012.12.004. e-pub ahead of print 2013/01/29

36. Watkins R, Goodwin VA, Abbott RA, Hall A, Tarrant M. Exploring residents' experiences of mealtimes in care homes: a qualitative interview study. BMC geriatrics. 2017;17:141-141. https://doi.org/10.1186/s12877-017-0540-2

37. Milte R, Ratcliffe J, Chen G, Miller M, Crotty M. Taste, choice and timing: Investigating resident and carer preferences for meals in aged care homes. Nurs Health Sci. 2018;20:116-24. https://doi.org/10.1111/nhs.12394. e-pub ahead of print 2018/01/10

38. Schlettwein-gsell D, Decarli B, de Groot L. Meal patterns in the SENECA study of nutrition and the elderly in Europe: assessment method and preliminary results 
on the role of the midday meal. Appetite. 1999;32:15-22. https://doi.org/10.1006/ appe.1998.0191. e-pub ahead of print 1999/02/17

39. Okkels SL, Dybdal DR, Beck AM, Bügel S, Klausen TW, Olsen A. An investigation of main meal preferences in nursing home residents. J Sens Stud. 2019;34:e12504 https://doi.org/10.1111/joss.12504

40. Buckinx F, Allepaerts S, Paquot N, Reginster JY, de Cock C, Petermans J, et al. Energy and nutrient content of food served and consumed by nursing home residents. J Nutr Health Aging. 2017;21:727-32. https://doi.org/10.1007/s12603016-0782-2. e-pub ahead of print 2017/05/26

41. Streicher M, Themessl-Huber M, Schindler K, Sieber CC, Hiesmayr M, Volkert D. nutritionDay in Nursing Homes-The Association of nutritional intake and nutritional interventions with 6-month mortality in malnourished residents. J Am Med Dir Assoc. 2017;18:162-8. https://doi.org/10.1016/j.jamda.2016.08.021. e-pub ahead of print 2016/10/11

42. Wirth R, Streicher $M$, Smoliner $C$, Kolb $C$, Hiesmayr $M$, Thiem $U$, et al. The impact of weight loss and low BMI on mortality of nursing home residents - Results from the nutritionDay in nursing homes. Clin Nutr. 2016;35:900-6. https://doi.org/ 10.1016/j.cInu.2015.06.003. e-pub ahead of print 2015/07/07

43. Salminen $K$, Suominen $M$, Kautiainen $H$, Roitto $H$, Pitkala K. Energy intake and severity of dementia are both associated with health-related quality of life among older long-term care residents. Nutrients 2019; 11. e-pub ahead of print 2019/09/ 25; https://doi.org/10.3390/nu11102261

44. Batchelor-Murphy M, Kennerly SM, Horn SD, Barrett R, Bergstrom N, Boss L, et al. Impact of cognition and handfeeding assistance on nutritional intake for nursing home residents. J Nutr Gerontol Geriatr. 2019;38:262-76. https://doi.org/10.1080/ 21551197.2019.1617221. e-pub ahead of print 2019/05/28

45. Volkert D, Chourdakis M, Faxen-Irving G, Frühwald T, Landi F, Suominen MH, et al. ESPEN guidelines on nutrition in dementia. Clin Nutr. 2015;34:1052-73. https:// doi.org/10.1016/j.clnu.2015.09.004

46. Berkhout AM, Cools HJ, van Houwelingen HC. The relationship between difficulties in feeding oneself and loss of weight in nursing-home patients with dementia. Age Ageing. 1998;27:637-41. https://doi.org/10.1093/ageing/27.5.637. e-pub ahead of print 2003/04/05

47. Crogan NL, Alvine C, Pasvogel A. Improving nutrition care for nursing home residents using the INRx process. J Nutr Elder. 2006;25:89-103. https://doi.org/ 10.1300/j052v25n03_07. e-pub ahead of print 2007/11/23

48. van Bokhorst-de van der Schueren MAE, Guaitoli PR, Jansma EP, de Vet HCW. A systematic review of malnutrition screening tools for the nursing home setting. J Am Med Dir Assoc. 2014;15:171-84. https://doi.org/10.1016/j.jamda.2013.10.006. e-pub ahead of print 2013/12/03

49. Shim JS, Oh K, Kim HC. Dietary assessment methods in epidemiologic studies. Epidemiol Health. 2014;36:e2014009 https://doi.org/10.4178/epih/e2014009. epub ahead of print 2014/08/01

50. Fewell Z, Davey Smith G, Sterne JAC. The impact of residual and unmeasured confounding in epidemiologic studies: a simulation study. Am J Epidemiol. 2007;166:646-55. https://doi.org/10.1093/aje/kwm165. e-pub ahead of print 2007/07/ 05

\section{ACKNOWLEDGEMENTS}

We thank all participating nursing homes for their contribution to the nutritionDay project. We are also grateful to the European Society for Clinical Nutrition (ESPEN) and all national medical nutrition societies, the Medical University Vienna and the Friedrich-Alexander-University Erlangen-Nürnberg for their support of the nutritionDay project. The present work was performed in partial fulfillment of the requirements for obtaining the degree Dr. rer. biol. hum (Doctoral Degree in Human Biology) for G.T. We acknowledge support by the MaNuEL knowledge hub and the Joint Programming Initiative Healthy Diet for a Healthy Life. The funding agencies supporting this work are (in alphabetical order of participating member state): Germany: German Federal Ministry of Food and Agriculture through the Federal Office for Agriculture and Food (Grants 2815ERA10E (FAU)); The Netherlands: The
Netherlands Organisation for Health Research and Development (ZonMw 50-5290598-499). The sponsors had no role in the design and conduct of the study, in the collection, analysis, or interpretation of data, or in the preparation, review, or approval of the manuscript.

\section{AUTHOR CONTRIBUTIONS}

Study concept and design: GT, MJH, EK, KS, CCS, MV, DV. Acquisition of data: FG, MJH, KS, DV, JW. Analysis and interpretation of data: GT, IS, MJH, EK, DV. Drafting of the manuscript: GT. Critical revision of the manuscript for important intellectual content: GT, IS, MJH, FG, EK, KS, CCS, MV, JW, DV.

\section{FUNDING}

Open Access funding enabled and organized by Projekt DEAL.

\section{COMPETING INTERESTS}

GT, IS, FG, EK, KS, CCS, MV, and JW declare no conflict of interest. CCS has no conflicts of interest related to the submitted manuscript. Outside the submitted work CCS has received honoraria and travel cost reimbursement for congress participation from Abbott, Baxter, Fresenius, Nestlé and Nutricia. MJH has no conflicts of interest related to the submitted manuscript. Outside the submitted work $\mathrm{MJH}$ has received honoraria and travel cost reimbursement for congress participation from Fresenius, SSPC, Nestlé and Baxter. Research work has been partially supported by unrestricted grants of Abbott and Fresenius to Medical University Vienna. DV has no conflicts of interest related to the submitted manuscript. Outside the submitted work DV has received grants from Nestec S.A., other from Nutricia, Fresenius. DV is a member of the Scientific Board of apetito AG.

\section{ADDITIONAL INFORMATION}

Supplementary information The online version contains supplementary material available at https://doi.org/10.1038/s41430-021-00964-9.

Correspondence and requests for materials should be addressed to G.T.

Reprints and permission information is available at http://www.nature.com/ reprints

Publisher's note Springer Nature remains neutral with regard to jurisdictional claims in published maps and institutional affiliations.

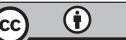

Open Access This article is licensed under a Creative Commons Attribution 4.0 International License, which permits use, sharing, adaptation, distribution and reproduction in any medium or format, as long as you give appropriate credit to the original author(s) and the source, provide a link to the Creative Commons license, and indicate if changes were made. The images or other third party material in this article are included in the article's Creative Commons license, unless indicated otherwise in a credit line to the material. If material is not included in the article's Creative Commons license and your intended use is not permitted by statutory regulation or exceeds the permitted use, you will need to obtain permission directly from the copyright holder. To view a copy of this license, visit http://creativecommons. org/licenses/by/4.0/.

(c) The Author(s) 2021 